\title{
Harmful alcohol use among mothers of under-five child: findings from the Panel Study on Korean Children
}

Seulgi Kim', Seung-Ah Choe ${ }^{2,3^{*}}$ and Sung- $\| \mathrm{Cho}^{1}$

\begin{abstract}
Background: Harmful alcohol use in young mothers as a primary caregiver has a profound impact on their own health and interaction with the child. We studied the epidemiology of harmful alcohol use among Korean mothers and their partners of under-five children.

Methods: We used a longitudinal data of 2,150 Korean mothers of the Panel Study on Korean Children (PSKC). We assessed temporal trend and risk factors for harmful alcohol use in mothers using generalized estimating equation (GEE) model. To estimate the impact of maternal harmful alcohol use on the child, the association between neurodevelopment of the child measured by the Korean-Ages \& Stages Questionnaire (K-ASQ) and maternal harmful alcohol use was analyzed using GEE and generalized linear mixed model. We included mother's age, education, preterm, year of the survey and time-varying covariates (including maternal working status, monthly household income, plan for additional childbirth, psychological stress related with childcare, current smoking, and partner's harmful alcohol use) in the model.
\end{abstract}

Results: Mean age of mothers at the baseline was 31.3 years. Annual prevalence of harmful alcohol use increased from $0.7 \%$ in the 1 st year to $2.6 \%$ in the 4 th year ( $P$ for linear trend $<0.001$ ). Prevalence of harmful alcohol use increased by $48 \%$ per year among the mothers (adjusted odds ratio $(\mathrm{OR})=1.48,95 \%$ confidence interval $(\mathrm{Cl}): 1.22$, 1.78). Lower education than college or university graduation was associated with higher odds of harmful alcohol use $(2.52,95 \% \mathrm{Cl}: 1.43,4.45)$. Current smoking $(7.44,95 \% \mathrm{Cl}: 3.00,18.45)$, harmful use of alcohol of partner $(2.66,95 \% \mathrm{Cl}$ : $1.57,4.49)$ were associated with higher risk of harmful alcohol use in mothers. The association between low K-ASQ score and maternal harmful alcohol use was toward positive which did not reach statistical significance.

Conclusions: In a cohort of Korean mothers participating in the PKSC, risk of harmful alcohol use increases over time and is associated with harmful alcohol use of their partners. We suggest an approach targeting both parents can be more effective in controlling the harmful alcohol use of mothers.

Keywords: Alcohol drinking, Substance-related disorders, Mothers, Under-5 children

*Correspondence: seungah@korea.ac.kr

${ }^{2}$ Department of Preventive Medicine, Korea University College

of Medicine, 73 Goryeodae-ro, Seongbuk-gu, Seoul 02841, Korea

Full list of author information is available at the end of the article

\begin{abstract}
Background
Harmful alcohol use is defined as alcohol consumption that results in physical or psychological harm [1]. It is a major contributor to cardiovascular disorders, gastrointestinal and/or liver problems, psychiatric diseases, and cancer [2]. Prevalence of harmful alcohol use in the general population widely ranges from $<1$ to $10 \%$ [1].
\end{abstract}

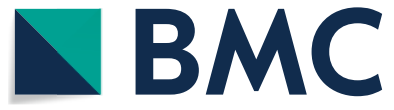

(O) The Author(s) 2021. This article is licensed under a Creative Commons Attribution 4.0 International License, which permits use, sharing, adaptation, distribution and reproduction in any medium or format, as long as you give appropriate credit to the original author(s) and the source, provide a link to the Creative Commons licence, and indicate if changes were made. The images or other third party material in this article are included in the article's Creative Commons licence, unless indicated otherwise in a credit line to the material. If material is not included in the article's Creative Commons licence and your intended use is not permitted by statutory regulation or exceeds the permitted use, you will need to obtain permission directly from the copyright holder. To view a copy of this licence, visit http://creativecommons.org/licenses/by/4.0/. The Creative Commons Public Domain Dedication waiver (http://creativecommons.org/publicdomain/zero/1.0//) applies to the data made available in this article, unless otherwise stated in a credit line to the data. 
Harmful alcohol use among parents of young children has life-long impacts on their own health and development of their children [3-5]. Although men are more likely to drink alcohol and drink in larger amounts, equal amounts of alcohol can cause more long-term impacts in women than men because of the biological difference in alcohol metabolism [5]. Specifically, the negative consequences of maternal alcohol consumption during pregnancy and parental alcohol consumption during childhood and adolescence on child development have been studied with a particular focus on fetal alcohol spectrum disorders (FASDs) [6]. During the postpartum including breast feeding period, harmful alcohol use was observed even in nursing women and the risk of harmful alcohol use was higher among those who became mothers in younger age [7-9]. Harmful alcohol use in mothers as a primary caregiver can also negatively affect interaction with the child and prenatal alcohol exposure of the second child $[10,11]$, more profoundly for the first 36 months of birth [12]. Children of alcohol-abusing parents are more likely to show alcohol or some other substance abuse and suffer from psychological disorders, poor academic performance compared to those with parents who do not abuse alcohol [13].

Given the profound impact of harmful alcohol use in the mothers, elucidating risk factors and potential targets of intervention would be important. Several maternal features including maternal precarious employment, low income, childcare-associated stress can be potential risk factors for substance use in mothers of young children which are not consistent in prior studies [6, 14-16]. In addition, pregnancy and childbirth can be a window of opportunity where women are more likely to be motivated to quit their substance abuse [8]. Using populationbased longitudinal cohort data, we assessed prevalence and risk factors for harmful alcohol use among mothers of under-five children born in 2008.

\section{Methods \\ Data}

We used the Panel Study on Korean Children (PSKC) conducted by the Korea Institute of Child Care and Education which is the first national panel study on newborn babies in Korea tracking the growth process of Korean children [17]. In brief, PSKC sampled babies born in health facilities across the country from April to July 2008 and then annually collected information of childrearing environment using self-administered questionnaires for the mothers and face-to-face interviews with trained interviewers [16]. To assess the prevalence of harmful alcohol use in mothers of young children, we restricted our analysis to the data of biological mothers of under 5-year children. The first wave in 2008 included
2,150 mother-baby pairs and $81.6 \%$ of the primary sample was retained in the 4th wave study in 2011 [18]. Information about participants' age, highest education, monthly income, employment status of the year, current smoking, harmful alcohol use and smoking of the partner, plan for additional childbirth, and parenting stress were obtained using self-administered questionnaires. Indeed, smoking has a strong association with alcohol use and vice versa $[19,20]$. Because majority of the primary daytime caregivers were mothers (84\%) in the PSKC [21], we focused on the epidemiology of maternal harmful alcohol use and its impact.

\section{Definition of harmful alcohol use and covariates}

We defined high-risk alcohol drinking as an average alcohol consumption of 5 drinks or more per occasion for women and 7 drinks or more for men twice or more per week [1, 16, 22]. We selected covariates including parent's age, education and employment status, monthly household income, harmful alcohol use and smoking, preterm birth and parenting stress scale based on previous studies $[15,16,23]$. Constant covariates were collected in 2008 survey and the answers classified into following categories: mothers' age $(<35$ and $\geq 35)$, highest education ( $\leq$ high school and college/university), and preterm birth as a proxy of the general health status of the baby. Annually collected information as time-varying covariates including employment status, current smoking, harmful alcohol use and current smoking of partner, plan for additional childbirth was grouped into two categories: yes or no. Unemployed included housewives and students. Monthly household income was classified in to 3 categories: $<\$ 3,442, \$ 3,442-6,885, \geq \$ 6,885$. The cut-off value for household income was based on the national median household income for 4-person families which was approximately $\$ 3,442$ per month in 2011 [24]. Parenting stress scale was measured pressures pertaining to parental role and distress using 10 questions which are used in a prior study [25]. The questions include, for example, the following statement: "I'm not sure if I can be a good parent", "I'm not sure if I can raise my child well", "Sometimes I want to run away from my child". We created a score as a sum of the responses to each question. We calculated a sum of all responses recorded with a 5point Likert scale and used it as a continuous measure for childcare stress of the year.

\section{Assessment of the neurodevelopment of children}

To estimate potential effect of the maternal harmful alcohol use on their children, we explored the association between maternal harmful alcohol use and the score of Korean-Ages \& Stages Questionnaire (K-ASQ). Between 2008 and 2010, the K-ASQ were administered by the 
mothers using Computer-assisted personal interviewing (CAPI) [26]. The Korean version of the ASQ has been validated and standardized for Korean children, based on the ASQ [27], which assesses 5 developmental domains: communication, fine motor skills, gross motor skills, personal and social skills, and problem-solving ability. Each domain is assessed by 6 questions and scores for individual items are summed to give a continuous score for each of the 5 domains ranging between 0 and 60 . The sensitivity of K-ASQ was $88 \%$ and specificity was $82.5 \%$ according to a prior report [28]. We identified infants with overall score of each domain is 2 SD below the mean which are indicative of development delay [29].

\section{Statistical analysis}

Annual composition of covariates and prevalence of parental harmful alcohol use for the first 4 years were calculated and tested for a linear trend using a weighted logistic regression method. To compare the associated factors of harmful alcohol use between mothers and their partners, a generalized estimating equation (GEE) model was conducted accounting for the within-woman correlation of repeated measurements. This approach is to estimate the population-average effects. We calculated odds ratio (OR) and confidence intervals (CI) of harmful alcohol use among mothers and their partners adjusted for age of mother and her partner, highest education, preterm birth, year of survey, and time-varying covariates (including maternal working status, monthly household income, plan for additional childbirth, psychological stress related with childcare, current smoking and partner's harmful alcohol use) $[15,16,23,25]$. To estimate potential impact of maternal harmful alcohol use, adjusted ORs of low score of K-ASQ (2 SD below the mean) for maternal harmful alcohol use were calculated. In further analyses, we fitted generalized linear mixed models calculating least-squares means of K-ASQ score. The score for each K-ASQ domain was converted into standardized value (z-score). Maternal current smoking was not included in the GEE model for K-ASQ scores because the prevalence was extremely low $(0.8 \%)$ in the K-ASQ responders. All statistical analysis was performed using SAS 9.4 (SAS Institute Inc.).

\section{Results}

Mean age of mothers at the first survey was $31.3 \pm 3.7$ years. Majority of women were college or university graduates, unemployed at the baseline survey (Table 1). Mothers whose baby is preterm was $4.5 \%$. The proportion of the employed among mothers increased over time. Overall, majority of women reported their monthly-average household income was below the national median level for 4-person families. Percentage of those who planned to have an additional child decreased in the fourth year. Proportion of highest quartile of parenting stress increased $(P<0.001)$. The annual prevalence of low K-ASQ score were between $0.3 \%$ and $5.3 \%$. Prevalence of low communication, fine motor and gross motor skills increased in the third year compared to those at the baseline.

When we analyze individual data, the odds of harmful alcohol use increased by $48 \%$ per year in mothers (adjusted OR $=1.48,95 \%$ CI: 1.22, 1.78, Table 2). Lower education than college or university graduation was associated with higher odds of harmful alcohol use $(2.52,95 \%$ CI: $1.43,4.45)$. In time-varying covariates, current smoking $(7.44,95 \%$ CI: 3.00, 18.45), harmful use of alcohol of partner $(2.66,95 \%$ CI: $1.57,4.49)$ were risk factors. Odds of harmful alcohol use was higher among those employed and lower household income, which did not reach statistical significance. We did not observe an association with age at the baseline survey, preterm baby, plan for additional childbirth, or childcare stress. In partners, harmful alcohol use increased over time $(1.07,95 \%$ CI: $1.02,1.11)$. This increasing trend was not evident for the annual prevalence of current smoking of partners in both mothers and their partners (data not shown). For partners, higher ORs were observed when the mothers show harmful alcohol use (1.87, 95\% CI1.23, 2.84).

The adjusted OR of low K-ASQ score were higher in the maternal harmful alcohol use group than in control group although the association did not reach statistical significance for all five domains (Table 3). Similarly, adjusted mean values of standardized K-ASQ score were lower when the mothers showed harmful alcohol use. There was no statistically significant difference in the mean scores of five domains between the two groups.

\section{Discussion}

We observed risk of harmful alcohol drinking consistently increases over time in mothers of under- 5 children using a sample of Korean mothers observed for 4 years. Lower education, current smoking, and harmful use of alcohol of partner were risk factors for harmful alcohol use of mothers. Contrast to general expectation, association with plan for additional childbirth and psychological stress related with childcare was not evident. The association between maternal harmful alcohol use and neurodevelopmental delay of the child was generally toward positive, though it did not reach statistical significance. Using longitudinal cohort data considering the temporal change in covariates, we added knowledge of annual increase and time-dependent risk factors of harmful alcohol use in mothers of under- 5 children.

The strength of our study is a population-based approach employing time-varying covariates 
Table 1 Change of demographic and behavioral characteristics of 2,150 mothers of Panel Study on Korean Children, 2008-2011

\begin{tabular}{|c|c|c|c|c|c|}
\hline \multicolumn{2}{|l|}{ Variables } & \multicolumn{2}{|c|}{2008,1 st year of survey } & & Weighted value \\
\hline Age, mean $\pm S D$ & & \multicolumn{2}{|c|}{$31.3 \pm 3.7$} & & $31.4 \pm 0.1$ \\
\hline Age of partner, mean \pm SD & & \multicolumn{2}{|c|}{$33.9 \pm 4.0$} & & $33.9 \pm 0.1$ \\
\hline \multicolumn{6}{|l|}{ Highest education } \\
\hline High school or lower, N (\%) & & \multicolumn{2}{|c|}{$644(30.9)$} & & $136,231(30.9)$ \\
\hline \multicolumn{6}{|l|}{ Highest education of partner } \\
\hline High school or lower education, N (\%) & & \multicolumn{2}{|c|}{$636(31.0)$} & & $136,354(31.0)$ \\
\hline \multicolumn{2}{|l|}{ Preterm baby, N (\%) } & \multicolumn{2}{|c|}{$90(4.5)$} & & $19,705(4.5)$ \\
\hline \multirow[t]{2}{*}{ Year of survey } & 2008 & 2009 & 2010 & 2011 & $P$ for trend ${ }^{b}$ \\
\hline & N (weighted \%) & N (weighted \%) & N (weighted \%) & N (weighted \%) & \\
\hline Employed mothers & $656(31.5)$ & $522(27.3)$ & $554(30.4)$ & $641(35.1)$ & 0.010 \\
\hline \multicolumn{6}{|l|}{ Monthly household income } \\
\hline$<3,442$ USD & $1,663(80.8)$ & $1,712(77.2)$ & $1,706(75.2)$ & $1,567(69.1)$ & $<.001$ \\
\hline $3,442-6,885$ USD & $377(18.0)$ & $354(19.3)$ & $385(19.3)$ & $525(27.8)$ & 0.673 \\
\hline$>6,885$ USD & $25(1.3)$ & $73(3.5)$ & $58(3.5)$ & $57(3.1)$ & - \\
\hline Plan for additional childbirth & $577(27.9)$ & $658(35.0)$ & $557(31.8)$ & $343(19.5)$ & $<.001$ \\
\hline \multicolumn{6}{|l|}{ Psychological stress related with childcare } \\
\hline 1st quartile & $728(34.1)$ & $542(28.6)$ & $432(24.1)$ & $452(25.7)$ & - \\
\hline 2nd quartile & $450(22.2)$ & $441(23.2)$ & $442(24.7)$ & $392(22.0)$ & 0.001 \\
\hline 3rd quartile & $439(21.1)$ & $435(23.3)$ & $417(22.9)$ & $389(22.3)$ & 0.001 \\
\hline 4th quartile & $461(22.6)$ & $486(24.9)$ & $511(28.4)$ & $521(30.0)$ & $<.001$ \\
\hline \multicolumn{6}{|l|}{ Low K-ASQ score ${ }^{c}$} \\
\hline Communication & $70(3.7)$ & $20(1.2)$ & $92(5.2)$ & - & 0.039 \\
\hline Fine motor skills & $12(0.4)$ & $34(2.0)$ & $30(1.7)$ & - & $<.001$ \\
\hline Gross motor skills & $7(0.3)$ & $93(5.3)$ & $32(2.1)$ & - & $<0.001$ \\
\hline Personal and social skills & $24(1.2)$ & $40(2.0)$ & $17(1.2)$ & - & 0.967 \\
\hline Problem-solving ability & $34(1.6)$ & $45(2.7)$ & $28(1.5)$ & - & 0.931 \\
\hline
\end{tabular}

SD, standard deviation; SE, standard error; K-ASQ, Korean-Ages \& Stages Questionnaire

a Converted from Korean Won to U.S. dollar (\$) based on the exchange rate in 2011 (1151.8 KW=1 USD)

${ }^{\mathrm{b}} P$ values for trend were calculated with the annual weighted prevalence

c Proportion of children whose score of the domain less than 2 standard deviation, higher score indicates better performance. There are 777 missing cases (12.2\%). The K-ASQ was not administered in 2011. Sum of column frequency may not be equal to 1 due to missing cases. Annual prevalence of harmful alcohol use increased from $0.7 \%$ in the 1 st year to $2.6 \%$ in the 4 th year $(P<0.001$ for linear trend, Fig. 1). Harmful alcohol use of their partners increased from $16.8 \%$ in the 1 st year to $22.1 \%$ in the 4th year $(P<0.001)$. Prevalence of current smoking remained as low as $0.8-1.2 \%$ throughout the study period $(P=0.216)$. Similarly, the prevalence of current smoking among their partners ranged between 50.9 and $53.4 \%$ without a significant linear trend

confirming well-known risk factors for harmful alcohol use among young women [17]. Prior studies showed low income, marriage, high perceived stress, and service occupation are risk factors for harmful alcohol use in women [16, 17]. Among women with young children, we additionally observed time since childbirth and partner's harmful alcohol use are associated with a higher risk of harmful alcohol use in mothers. In a study of biological parents of under 5 children, they observed an association between father's regular alcohol use and children's developmental delay mediated by less-skilled maternal parenting practices [13]. We postulate the increasing risk of harmful alcohol use over time can be due to their limited choice in the measures to relieve their stress, given their burden of house chores and childcare [18]. Especially for alcohol use, studies have shown gender differences in stressrelated alcohol use: women are generally more likely to drink to regulate negative affect and stress reactivity while men may be more likely to drink for positive reinforcement [30].

The positive association between gender role or equality and alcohol consumption in men and women is reported in prior studies [23, 31]. In countries with higher levels of gender equality where men are more involved in childcare, men, as well as women, may be more likely to reduce their alcohol consumption when they live with children [23]. Given the high gender-based inequality in 


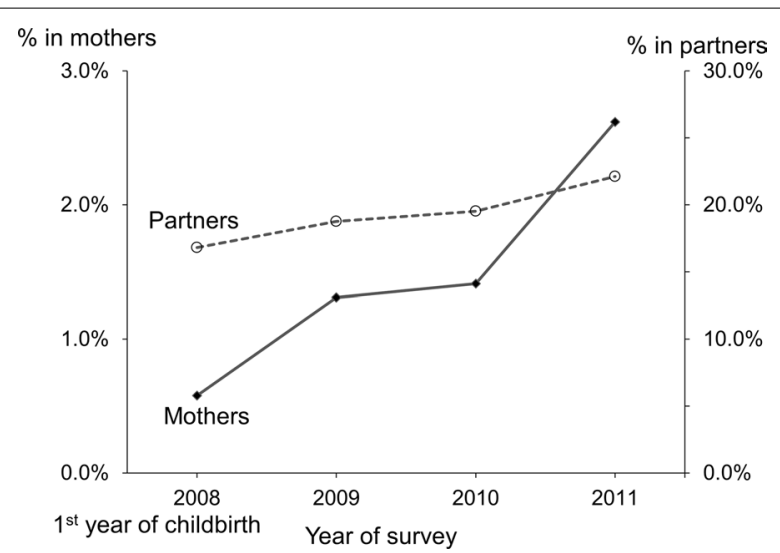

Fig. 1 Annual weighted prevalence of harmful alcohol use among mothers $(n=2,150)$ and their partners $(n=1,828)$ of the Panel Study on Korean Children, 2008-2011 childcare in Korea [31], this also may explain the mutual increase in the prevalence in both parents in this study.

Prior studies reported maternal substance use is associated with psychological and developmental problems of their offspring $[4,13]$. We observed some evidence of higher risk of delayed neurodevelopment measured by K-ASQ, though the association did not reach statistical significance. This result could be due to the low prevalence of delayed neurodevelopment in the study participants. Given the consistent pattern of higher risk of delayed neurodevelopment, we believe this finding of positive association could be replicated when the neurodevelopmental delay is more prevalent.

The finding of this study needs caution in interpretation. First, there has been no information on additional childbirths during the survey. Women who were pregnant at the time of the survey would have been less likely to use alcohol. However, based on our finding of closeto-null association between plan for additional childbirth

Table 2 Adjusted odds ratio of harmful alcohol use and current smoking using generalized estimating equation models, 2,150 mothers and their partners of Panel Study on Korean Children, 2008-2011

\begin{tabular}{|c|c|c|}
\hline \multirow[t]{3}{*}{ Covariates } & \multicolumn{2}{|c|}{ Odds ratios (95\% Confidence intervals) ${ }^{b}$} \\
\hline & \multicolumn{2}{|c|}{ Harmful alcohol drinking } \\
\hline & Mothers & Fathers \\
\hline Baseline year, 2008 & 1.00 (reference) & \\
\hline Linear effect of year & $1.48(1.22,1.78)$ & $1.07(1.02,1.11)$ \\
\hline Age $\geq 35$ years & $1.18(0.60,2.30)$ & $1.28(1.06,1.54)$ \\
\hline Preterm birth & $0.73(0.16,3.33)$ & $0.80(0.50,1.29)$ \\
\hline \multicolumn{3}{|l|}{ Highest education } \\
\hline High-school or lower & $2.52(1.43,4.45)$ & $1.26(1.03,1.54)$ \\
\hline College/University & 1.00 (reference) & 1.00 (reference) \\
\hline \multicolumn{3}{|l|}{ Time-varying covariates } \\
\hline \multicolumn{3}{|l|}{ Employment } \\
\hline Employed & $1.59(0.97,2.59)$ & - \\
\hline Unemployed/housewife & 1.00 (reference) & - \\
\hline \multicolumn{3}{|l|}{ Monthly household income ${ }^{a}$} \\
\hline$<3,442$ USD & $1.42(0.35,5.84)$ & $0.68(0.52,0.90)$ \\
\hline 3,442-6,885 USD & $1.22(0.28,5.43)$ & $0.65(0.49,0.86)$ \\
\hline$>6,885$ USD & 1.00 (reference) & 1.00 (reference) \\
\hline Current smoking & $7.44(3.00,18.45)$ & $2.33(1.97,2.75)$ \\
\hline Harmful use of alcohol & - & - \\
\hline Plan for childbirth & $1.03(0.60,1.76)$ & - \\
\hline Psychological stress related with childcare & $1.25(0.99,1.57)$ & - \\
\hline Harmful use of alcohol of partner & $2.66(1.57,4.49)$ & $1.87(1.23,2.84)$ \\
\hline Smoking of partner & $1.40(0.74,2.62)$ & $1.10(0.65,1.85)$ \\
\hline
\end{tabular}

Estimates with $P<0.05$ were bolded

a Converted from Korean Won to U.S. dollar (\$) based on the exchange rate in 2011 (1 USD =1151.8 KW)

b Calculated using generalized estimating equation models including the effect of maternal and paternal age, highest education, preterm birth, year of survey and time-varying covariates (including maternal working status, monthly household income, plan for additional childbirth, psychological stress related with childcare and partner's harmful alcohol use) 
Table 3 Adjusted odds ratio (OR) of low score (<2 SD) for each domain of the Korean-Ages \& Stages Questionnaire (K-ASQ) and adjusted means of K-ASQ score, 1,891 ${ }^{\mathrm{a}}$ children aged 0-2 of Panel Study on Korean Children, 2008-2010

\begin{tabular}{|c|c|c|c|c|c|c|}
\hline \multirow[t]{2}{*}{ K-ASQ domain } & \multicolumn{2}{|l|}{ Adjusted OR $(95 \% \mathrm{Cl})^{\mathrm{b}}$} & \multirow[t]{2}{*}{$P$} & \multicolumn{2}{|c|}{ Adjusted mean K-ASQ score (standardized) ${ }^{c}$} & \multirow[t]{2}{*}{$P$ for difference } \\
\hline & No harmful alcohol use & Harmful alcohol use & & No harmful alcohol use & Harmful alcohol use & \\
\hline Communication & 1.00 (reference) & $1.47(0.43,5.08)$ & 0.543 & $0.02(-0.04,0.09)$ & $-0.18(-0.46,0.10)$ & 0.148 \\
\hline Fine motor skills & 1.00 (reference) & $2.49(0.51,12.07)$ & 0.258 & $0.02(-0.05,0.08)$ & $-0.22(-0.51,0.06)$ & 0.096 \\
\hline Gross motor skills & 1.00 (reference) & $1.54(0.35,6.73)$ & 0.569 & $0.06(0.00,0.12)$ & $-0.08(-0.35,0.18)$ & 0.275 \\
\hline Personal and social skills & 1.00 (reference) & $1.48(0.20,11.00)$ & 0.702 & $-0.04(-0.11,0.03)$ & $-0.27(-0.55,0.02)$ & 0.110 \\
\hline Problem-solving ability & 1.00 (reference) & $2.32(0.51,10.61)$ & 0.279 & $-0.02(-0.09,0.05)$ & $-0.08(-0.36,0.21)$ & 0.680 \\
\hline
\end{tabular}

K-ASQ, Korean-Ages \& Stages Questionnaire; OR, odds ratio; Cl, confidence interval

a There are 777 missing cases (12.2\%) and the K-ASQ was not administered in 2011

b Calculated using generalized estimating equation models including the effect of maternal and paternal age, highest education, preterm birth, year of survey and time-varying covariates (including maternal working status, monthly household income, plan for additional childbirth, psychological stress related with childcare and partner's harmful alcohol use)

c Calculated using generalized linear mixed models (GLMM). Maternal current smoking was not included in the GEE model for K-ASQ scores because the prevalence was extremely low (0.8\%) in the K-ASQ population

and harmful use of alcohol, we believe the potential confounding effect in our estimation would be minimal. Second, the data on pre-pregnancy alcohol use was absent in our study which could have potentially confounded the association between harmful alcohol use of mothers and the neurodevelopment of their young children. To address the independent effect of maternal alcohol use during childcare, adjusting the association for mothers' pre-pregnancy substance use would be important. However, our primary research question was about the patterns and risk factors of harmful alcohol use in mothers of under- 5 children who are presumably motivated to change their drinking behavior. Therefore, our study finding would still have implications in providing some evidence for effective strategies for reducing harmful alcohol use in mothers.

\section{Conclusions}

We observed the harmful alcohol use among mothers of under- 5 children is associated with lower education, current maternal smoking, and harmful use of alcohol of their partner. Based on this finding, we suggest a comprehensive approach which can reduce the harmful alcohol use in both parents for more effective public health intervention during the early years of childbirth.

\section{Abbreviations}

GEE: Generalized estimating equation; PSKC: Panel Study on Korean Children; OR: Odds ratio.

\section{Acknowledgements}

We are thankful to the KICCE for providing the data.

\section{Authors' contributions}

SK conducted primary statistical analysis and wrote the draft. SAC reviewed and revised the draft. SIC supervised the process of study. All authors read and approved the final manuscript.

\section{Funding}

This research was supported by a Korea University Grant (K2022961) and a Korea University Medical Center Grant (K2025301). This funding source had no role in study design, in the collection, analysis and interpretation of data, in the writing of the report, and in the decision to submit the article for publication. The contents of this report are solely the responsibility of the authors and do not necessarily represent the official views of the sponsoring organizations.

\section{Availability of data and materials}

The data used in this study is available to individual researchers or institutions upon approval of the Korea Institute of Child Care and Education (KICCE, https://kicce.re.kr)

\section{Declarations}

\section{Ethics approval and consent to participate}

The PSKC was approved by the Korea Institute of Child Care and Education Institutional Review Board (No. KICCEIRB-2018-02). The informed consent was obtained at the time of participation in the study. All methods were carried out in accordance with relevant guidelines and regulations.

\section{Consent for publication}

Not applicable.

\section{Competing interests}

None.

\section{Author details \\ ${ }^{1}$ Department of Public Health Science, Graduate School of Public Health, Seoul National University, Seoul 08826, Korea. ${ }^{2}$ Department of Preventive Medicine, Korea University College of Medicine, 73 Goryeodae-ro, Seong- buk-gu, Seoul 02841, Korea. ${ }^{3}$ Department of Epidemiology and Health Infor- matics, Graduate School of Public Health, Korea University, 73 Goryeodae-ro, Seongbuk-gu, Seoul 02841, Korea.}

Received: 17 January 2021 Accepted: 12 April 2021

Published online: 17 April 2021

References

1. Reid MC, Fiellin DA, O'Connor PG. Hazardous and harmful alcohol consumption in primary care. Arch Intern Med. 1999;159(15):1681-9.

2. WHO: Global status report on alcohol and health 2018; 2018.

3. Zeitlin H. Children with alcohol misusing parents. Br Med Bull. 1994;50(1):139-51. 
4. Raitasalo K, Holmila M, Jaaskelainen M, Santalahti P. The effect of the severity of parental alcohol abuse on mental and behavioural disorders in children. Eur Child Adolesc Psychiatry. 2019;28(7):913-22.

5. Solis JM, Shadur JM, Burns AR, Hussong AM. Understanding the diverse needs of children whose parents abuse substances. Curr Drug Abuse Rev. 2012;5(2):135-47.

6. May PA, Blankenship J, Marais AS, Gossage JP, Kalberg WO, Joubert B, Cloete M, Barnard R, De Vries M, Hasken J, et al. Maternal alcohol consumption producing fetal alcohol spectrum disorders (FASD): quantity, frequency, and timing of drinking. Drug Alcohol Depend. 2013;133(2):502-12.

7. May PA, Hasken JM, Blankenship J, Marais AS, Joubert B, Cloete M, de Vries MM, Barnard R, Botha I, Roux S, et al. Breastfeeding and maternal alcohol use: prevalence and effects on child outcomes and fetal alcohol spectrum disorders. Reprod Toxicol. 2016;63:13-21.

8. Laborde ND, Mair C. Alcohol use patterns among postpartum women. Matern Child Health J. 2012;16(9):1810-9.

9. De Genna NM, Goldschmidt L, Marshal M, Day NL, Cornelius MD. Maternal age and trajectories of risky alcohol use: a prospective study. Alcohol Clin Exp Res. 2017:41(10):1725-30.

10. Damashek A, Williams NA, Sher K, Peterson L. Relation of caregiver alcohol use to unintentional childhood injury. J Pediatr Psychol. 2009;34(4):344-53.

11. Varnaccia G, Manz K, Zeiher J, Rattay P, Lange C. Risky alcohol consumption and heavy episodic drinking among parents in Germany: results of a nationwide cross-sectional study. J Environ Public Health. 2019:2019:3673479.

12. Lugo-Gil J, Tamis-LeMonda CS. Family resources and parenting quality: links to children's cognitive development across the first 3 years. Child Dev. 2008;79(4):1065-85.

13. Guttmannova K, Hill KG, Bailey JA, Hartigan L, Small CM, Hawkins JD. Parental alcohol use, parenting, and child on-time development. Infant Child Dev. 2017;26(5):e2013.

14. Floyd RL, Decouflé $P$, Hungerford DW. Alcohol use prior to pregnancy recognition. Am J Prev Med. 1999;17(2):101-7.

15. Shmulewitz D, Hasin DS. Risk factors for alcohol use among pregnant women, ages 15-44, in the United States, 2002 to 2017. Prev Med. 2019:124:75-83

16. Choe SA, Yoo S, JeKarl J, Kim KK. Recent trend and associated factors of harmful alcohol use based on age and gender in Korea. J Korean Med Sci. 2018;33(4):e23.

17. Park E, Kim YS. Gender differences in harmful use of alcohol among Korean adults. Osong Public Health Res Perspect. 2019;10(4):205-14.

18. Irani L, Vemireddy V. Getting the measurement right! quantifying time poverty and multitasking from childcare among mothers with children across different age groups in rural north India. Asian Popul Stud. 2020;17(1):94-116.

19. Burling TA, Ziff DC. Tobacco smoking: a comparison between alcohol and drug abuse inpatients. Addict Behav. 1988;13(2):185-90.

20. Miller NS, Gold MS. Comorbid cigarette and alcohol addiction: epidemiology and treatment. J Addict Dis. 1998;17(1):55-66.

21. Forouzanfar MH, Afshin A, Alexander LT, Anderson HR, Bhutta ZA, Biryukov S, Brauer M, Burnett R, Cercy K, Charlson FJ, et al. Global, regional, and national comparative risk assessment of 79 behavioural, environmental and occupational, and metabolic risks or clusters of risks, 1990-2015: a systematic analysis for the Global Burden of Disease Study 2015. The Lancet. 2016;388(10053):1659-724.

22. Rehm J, Crepault JF, Wettlaufer A, Manthey J, Shield K. What is the best indicator of the harmful use of alcohol? A narrative review. Drug Alcohol Rev. 2020;39(6):624-31

23. Graham K, Bernards S, Karriker-Jaffe KJ, Kuntsche S, Laslett AM, Gmel G, Callinan S, Stanesby O, Wells S. Do gender differences in the relationship between living with children and alcohol consumption vary by societal gender inequality? Drug Alcohol Rev. 2020;39(6):671-83.

24. Latest welfare news. http://www.bokjiro.go.kr/news/allNewsView.do? board_sid $=308 \&$ data_sid $=6060539$.

25. Ki HK, Kang HK. Development of the parenting stress scale. Fam Environ Res. 1997;35(5):141-50.

26. Nari Shin JL, Kim MJ, Kim YW, Hong SH, Lee KJ. Panel study on Korean children: a pilot study. 2007, 2021(Mar 28).

27. Heo KY, Squire J, Lee SY, Squires J, Potter LW, Bricker D. K-ASQ manual Seoul: Seoul Community Rehabilitation Center; 2006.

28. Yu L-M, Hey E, Doyle LW, Farrell B, Spark P, Altman DG, Duley L. Evaluation of the Ages and Stages Questionnaires in identifying children with neurosensory disability in the Magpie Trial follow-up study. Acta Paediatr. 2007:96(12):1803-8.

29. Kim M, Kang SK, Yee B, Shim SY, Chung M. Paternal involvement and early infant neurodevelopment: the mediation role of maternal parenting stress. BMC Pediatr. 2016;16(1):212.

30. Peltier MR, Verplaetse TL, Mineur YS, Petrakis IL, Cosgrove KP, Picciotto MR, McKee SA. Sex differences in stress-related alcohol use. Neurobiol Stress. 2019;10:100149.

31. Shin Y-J. Changes in time spent on housework and child care among Korean parents. Korean Institute for Health and Social Affairs; 2015.

\section{Publisher's Note}

Springer Nature remains neutral with regard to jurisdictional claims in published maps and institutional affiliations.
Ready to submit your research? Choose BMC and benefit from:

- fast, convenient online submission

- thorough peer review by experienced researchers in your field

- rapid publication on acceptance

- support for research data, including large and complex data types

- gold Open Access which fosters wider collaboration and increased citations

- maximum visibility for your research: over 100M website views per year

At $B M C$, research is always in progress.

Learn more biomedcentral.com/submissions 